\title{
Interring Gas Dynamic Analysis of Piston in a Diesel Engine considering the Thermal Effect
}

\author{
Wanyou Li, ${ }^{1}$ Yibin Guo, ${ }^{1}$ Tao He, ${ }^{1,2}$ Xiqun Lu, ${ }^{1}$ and Dequan Zou ${ }^{1,2}$ \\ ${ }^{1}$ College of Power and Energy Engineering, Harbin Engineering University, Harbin, Heilongjiang 150001, China \\ ${ }^{2}$ Washington University in St. Louis, St. Louis, MO 63108, USA \\ Correspondence should be addressed to Wanyou Li; hrbeu_ripet_lwy@163.com
}

Received 28 August 2014; Accepted 10 November 2014

Academic Editor: Woo-Young Jung

Copyright (c) 2015 Wanyou Li et al. This is an open access article distributed under the Creative Commons Attribution License, which permits unrestricted use, distribution, and reproduction in any medium, provided the original work is properly cited.

\begin{abstract}
Understanding the interaction between ring dynamics and gas transport in ring pack systems is crucial and needs to be imperatively studied. The present work features detailed interring gas dynamics of piston ring pack behavior in internal combustion engines. The model is developed for a ring pack with four rings. The dynamics of ring pack are simulated. Due to the fact that small changes in geometry of the grooves and lands would have a significant impact on the interring gas dynamics, the thermal deformation of piston has been considered during the ring pack motion analysis in this study. In order to get the temperature distribution of piston head more quickly and accurately, an efficient method utilizing the concept of inverse heat conduction is presented. Moreover, a sensitive analysis based on the analysis of partial regression coefficients is presented to investigate the effect of groove parameters on blowby.
\end{abstract}

\section{Introduction}

The piston ring performs its function as a seal of high and low pressure sides in a cylinder and a medium of heat transfer from piston to cylinder walls. The operation of piston ring packs influences the performance, efficiency, durability, and emissions of engines in terms of friction, wear, oil consumption, and gas blowby. For those reasons, the performance of piston rings in combustion engines has been a topic of research for many years. Ting and Mayer $[1,2]$ developed early models of ring lubrication and blowby. Their models were aimed at the eventual prediction of cylinder wear. The work of Dowson et al. [3] and Ruddy et al. $[4,5]$ has resulted in the development of more integrated simulations, which include effects of ring dynamics. Rhode [6] has incorporated into ring lubrication calculations a model of mixed lubrication, which allows more realistic calculation of ring friction; it has been so since adopted by a number of other investigators. The effort toward further integration of various submodels into what has become an established scheme of two-dimensional axisymmetric analysis of ring packs has continued in the eighties [7], with more studies involving various design parameters as well as comparison to data $[8,9]$.
Classical theory of lubrication is based on the Reynolds equation, which can be derived from control volume analysis under certain simplifying assumptions. This equation calculates the oil film pressure given the film thickness, squeeze velocity, and the pressure at the boundaries (typically ambient pressure). Then attention had been shifting from ring dynamics and blowby, which can be predicted with reasonable accuracy, to the modeling of oil consumption, the accuracy of the current oil consumption models [9-11]. Keribar et al. [12] developed an integrated model of piston ring pack including ring-liner hydrodynamic and boundary lubrication, ring axial, radial, and twist dynamics, interring gas dynamics, and blowby. Blow-by gas flow refers to the undesired gas flow from combustion chamber to the crankcase. It reduces the efficiency of the engine and contaminates oil with the combustion products present in the gases; the ring pack system serves as a channel for blow-by gases. As a result, it is important for engine manufacturers and lubricant suppliers to optimize ring pack system to take it into account in controlling oil consumption resulting from blow-by gases. Such research pursues to decrease the amount of blow-by gas flow while upholding sufficient lubrication and minimum friction. 
Most of the existing models above are based on the axisymmetric assumption, called 2D models. With the help of these 2D models, a great deal of detailed analysis of ring lubrication has been performed and some conclusions have been used successfully in guiding the practical application [13]. The efforts to model the ring dynamics in 3D manner can also be found in the publications. Tian et al. [14] presented ring dynamics and gas flow model to study ring/groove contact, blowby, and the influence of ring static twist, keystone ring/groove configurations, and other piston ring parameters. Ejakov et al. [15] simulated the dynamic twist angle of the piston ring pack along the circumference by using finite element analysis. In [16], a combination of a detailed elastic analysis and a complementarity method was used to evaluate the ring/bore conformability in an accurate way. Ma $[17,18]$ implemented a flow-continuity algorithm in the hydrodynamic lubrication submodel, which ensured an accurate oil transport simulation. Liu [19] developed a piston ring pack model considering nonaxisymmetric characteristics of power cylinder system considering oil transport along the liner. The oil transport along the ring pack system is driven by the motion of the piston rings [20]. Sometimes, oil is entrained in blow-by gases, transported within the ring pack. The demonstration of the interaction between ring performance and gas transport can help to understand oil transport mechanism and lead to effective ways of reducing the oil consumption. Li [21] took the ring geometry, assembly load, and mechanical and thermal properties into consideration in their simulation of piston ring behavior.

In order to know the ring pack motion, the most important part is to analyse the interring gas dynamic. Due to the fact that small changes in geometry of the grooves, lands, and bore would have a significant impact on the interring gas dynamics, the thermal deformation should be taken into consideration during ring pack motion analysis. In order to determine the thermal deformation of bore and piston, a 2D finite element (FE) model is used in this study. In the thermal analysis part, an efficient method utilizing the concept of inverse heat conduction is presented to get the temperature distribution of piston. After getting the temperature distribution of piston, a thermostructure analysis is presented to get the deformation of piston lands and grooves and bore, as the input data for ring pack dynamics and tribological analysis. The second part of this study focuses on the interring gas dynamics of piston ring pack behavior in internal combustion engines. The model is developed for a ring pack with four rings. The dynamics of the top three rings and the gas pressure in the regions about the oil control ring are simulated.

\section{Modeling of Piston Ring Pack Dynamics}

The motion of piston ring within the piston groove can be described by the axial rotational (toroidal twist) and radial motions in the three respective degrees of freedom. The ring motion in the circumference direction is neglected in this study. As shown in Figure 1, a small section for the ring at a

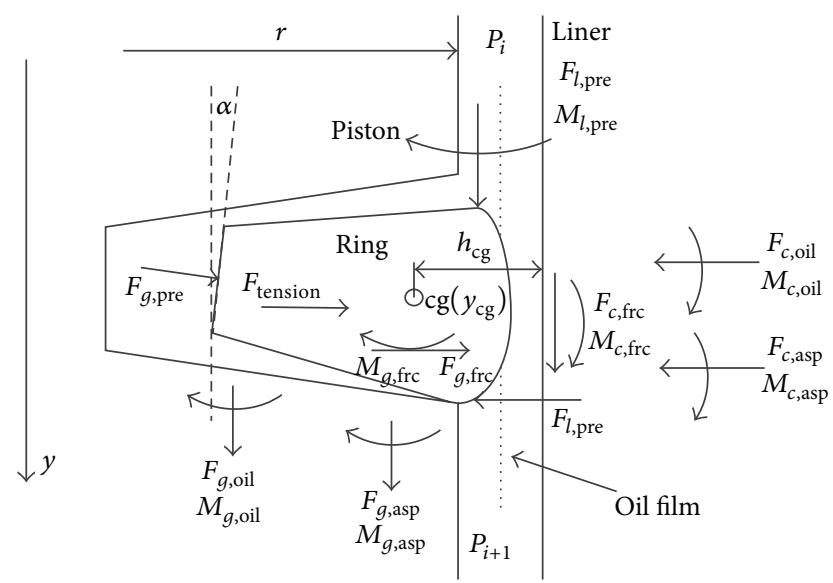

FIGURE 1: Free body diagram of ring cross-section.

circumferential location is considered. The governing equations for the ring motion are written as

$$
\begin{aligned}
m_{r} \frac{d^{2} y_{\mathrm{cg}}}{d t^{2}}= & F_{g, \text { oil }}+F_{g, \text { asp }}+F_{c, \text { frc }}-F_{l, \mathrm{pre}}-m_{r} g, \\
I_{r} \frac{d^{2} \alpha}{d t^{2}}= & M_{g, \text { oil }}+M_{g, \text { asp }}+M_{c, \text { frc }} \\
& +M_{l, \text { pre }}+M_{c, \text { oil }}+M_{c, \text { asp }}-K_{r t} \alpha, \\
m_{r} \frac{d^{2} h_{\mathrm{cg}}}{d t^{2}}= & F_{g, \text { pre }}+F_{g, \text { frc }}+F_{c, \text { oil }} \\
& \quad F_{c, \text { asp }}-F_{l, \text { pre }}^{\prime}+K_{r r}\left(h^{\prime}+h_{0}\right),
\end{aligned}
$$

where $y_{\mathrm{cg}}$ and $h_{\mathrm{cg}}$ are the axial and radial position of the center of gravity of the ring and $\alpha$ is the twist angle. $m_{r}$, $I_{r}$, and $K_{r t}$ are ring mass, moment of inertia for toroidal rotation, and cross-sectional torsional stiffness. $K_{r r}$ is the radial tension stiffness, $h^{\prime}$ the reduction in ring radius at installation, and $h_{0}$ the minimum ring-bore oil film thickness $\left(F_{\text {tension }}=K_{r r}\left(h^{\prime}+h_{0}\right)\right)$. F's and $M$ 's are forces and moments acting on the ring cross-section, as shown in the free body diagrams of Figures 1 and 2. In terms of forces and moments in (1) the first subscript indicates location on the ring $(g=$ groove, $c=$ cylinder, and $l=$ land) and the second subscript describes the source of the force or moment (oil = oil pressure, asp $=$ normal pressure due to asperity contact, pre $=$ gas pressure, and frc = hydrodynamic or boundary friction). The torsional moment $M_{r t}$ is calculated as

$$
M_{r t}=K_{r t} \alpha .
$$

For a complete ring with rectangular cross-section, the cross-sectional torsional stiffness $\left(K_{r t}\right)$ is given by

$$
K_{r t}=\frac{E b^{3} \ln (D / d)}{3(D+d)}
$$

where $E$ is the modulus of elasticity of piston ring, $b$ is the axial height of piston ring section, $d$ is the inner diameter, 


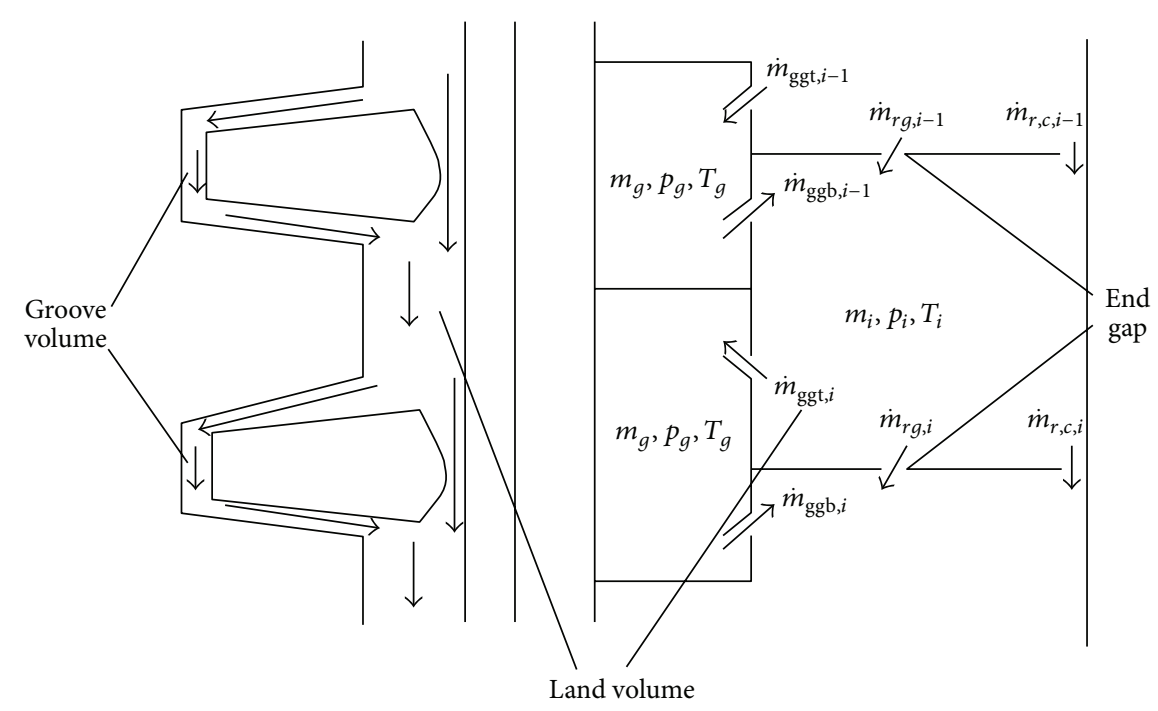

FIGURE 2: Gas volumes and gas flow paths in ring pack.

and $D$ is the outer diameter of piston ring. The axial motion of a ring relative to piston can be expressed as

$$
\begin{gathered}
y_{\mathrm{cg}}=y_{p}+y_{r p}, \\
\frac{d y_{\mathrm{cg}}}{d t}=\frac{d y_{p}}{d t}+\frac{d y_{r p}}{d t}, \\
\frac{d^{2} y_{\mathrm{cg}}}{d t^{2}}=\frac{d^{2} y_{p}}{d t^{2}}+\frac{d^{2} y_{r p}}{d t^{2}},
\end{gathered}
$$

where $y_{p}$ is the axial position of the piston and $y_{r p}$ is the axial position of the ring related to the piston.

Forces and moment associated with land and groove gas pressure are calculated using pressure solutions from gas dynamics submodel. Those associated with oil pressure are obtained from the lubrication submodel, and those associated with local asperity contact pressure are calculated by asperity deformation model. Ring axial position and twist influence gas flow paths and the forces at the ring groove interface. Ring twist also affects the effective profile presented by the ring face to the cylinder bore and thus oil film thickness and ring friction. The lubrication model, asperity deformation model, and oil film squeezing model at ring side and groove interface have specific introduction in $[12,14]$.

\section{Interring Gas Dynamics}

The gas flow between the rings and groove flanks and the flow behind the ring are calculated based on the actual interring volumes due to actual clearances and ring positions. The real mass flow rate is determined from the ideal flow by use of discharge coefficients. The purpose of the interring gas dynamics model is the calculation of the rate of gas blowby through the leakage paths between series of gas volumes. The gas volumes in ring grooves as well as ring-lands are considered and calculated from the piston, groove, and ring geometries and positions, as shown in Figure 2. The leakage paths are the gaps between rings and grooves (due to areas that become available during ring motions in grooves), the gaps between the ring face and cylinder bore (due to ring lift), and the ring-end gaps. The blowby is assumed to be an unsteady adiabatic flow satisfying the perfect gas law. It is also assumed that the combustion chamber pressure versus crank angle relation remains unaffected despite the gas leakage. The continuity equations for the land and groove gas volumes are written as

$$
\begin{gathered}
\frac{d m_{l, i}}{d t}=\dot{m}_{\mathrm{leg}, i-1}+\dot{m}_{\mathrm{ggb}, i-1}+\dot{m}_{\mathrm{rlg}, i-1}-\dot{m}_{\mathrm{geg}, i} \\
-\dot{m}_{\mathrm{gg}, i}-\dot{m}_{\mathrm{rlg}, i}, \quad(i=2, \ldots, N), \\
\frac{d m_{g, i}}{d t}=\dot{m}_{\mathrm{ggt}, i}+\dot{m}_{\mathrm{ggg}, i}-\dot{m}_{\mathrm{gg} b, i}-\dot{m}_{\mathrm{leg}, i}, \quad(i=1, \ldots, N),
\end{gathered}
$$

where $m$ is the mass of gas in volume and $\dot{m}$ denotes the mass flow rate through the various flow paths identified by subscripts "leg"/"geg" (ring-end gaps connected to groove volume and connected to land volume), "ggt"/"ggb" (ring groove gaps above and below ring), and "rlg" (ring-left gaps). For the first land volume, the continuity equation is

$$
\frac{d m_{l, 1}}{d t}=\dot{m}_{\mathrm{lin}, 1}-\dot{m}_{\mathrm{geg}, 1} \dot{m}_{\mathrm{ggt}, 1}-\dot{m}_{\mathrm{rlg}, 1},
$$

where $\dot{m}_{\text {lin, } 1}$ is the mass flow rate through the gap between piston and bore at the piston top position. The gas flow rates through the flow paths are calculated by the following relationship.

$$
\begin{aligned}
& \text { If } \begin{aligned}
p_{d} / p_{u}> & (2 /(\gamma+1))^{\gamma /(\gamma-1)}, \\
\dot{m}= & C_{f} A\left(\frac{2 \gamma}{R(\gamma+1) T_{u}}\right)^{1 / 2} \\
& \cdot p_{u}\left(\frac{p_{d}}{p_{u}}\right)^{1 / \gamma}\left[1-\left(\frac{p_{d}}{p_{u}}\right)^{(\gamma-1) / \gamma}\right]^{1 / 2} .
\end{aligned}
\end{aligned}
$$




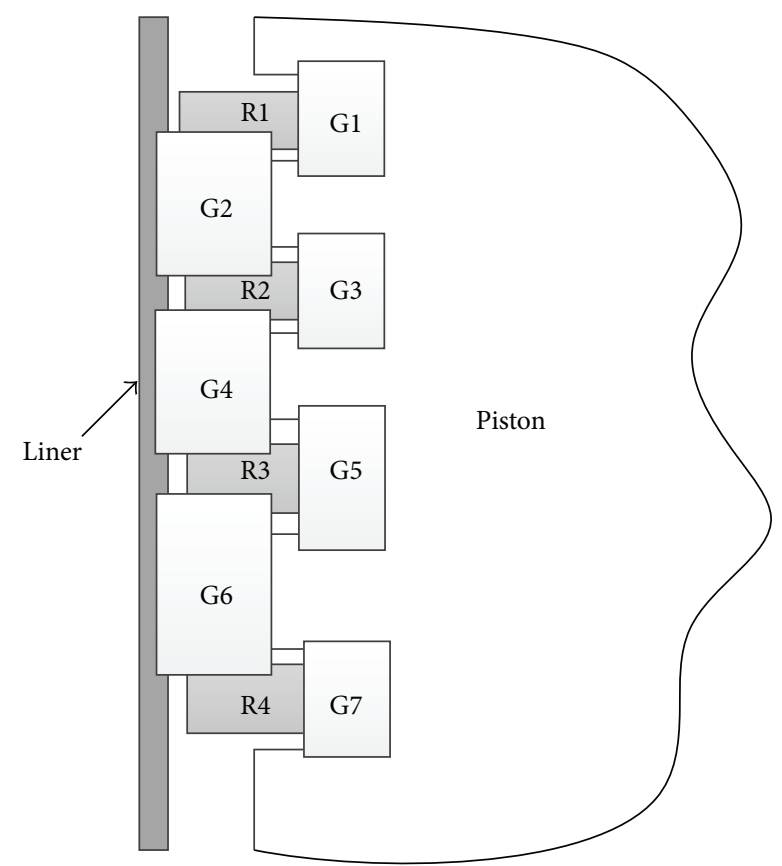

FIGURE 3: Gas zones during piston ring pack dynamic.

$$
\begin{aligned}
& \text { If } \begin{aligned}
p_{d} / p_{u} \leq & (2 /(\gamma+1))^{\gamma /(\gamma-1)}, \\
\dot{m}= & C_{f} A\left(\frac{2 \gamma}{R(\gamma+1) T_{u}}\right)^{1 / 2} \\
& \cdot p_{u}\left(\frac{2}{\gamma+1}\right)^{1 /(\gamma-1)}\left[1-\left(\frac{2}{\gamma+1}\right)\right]^{1 / 2} .
\end{aligned}
\end{aligned}
$$

In (7) and (8), $C_{f}$ is the orifice flow coefficient, $A$ is the orifice area, $R$ and $\gamma$ are the gas constant and polytropic exponent, $p_{u}$ and $p_{d}$ are pressure upstream and downstream of the orifice, and $T_{u}$ is the upstream temperature.

The gas equation of state is applied to land volumes and the groove volumes:

$$
\begin{gathered}
p_{l, i} V_{l, i}=m_{l, i} R T_{l, i}, \quad(i=1, \ldots, N), \\
p_{g, i} V_{g, i}=m_{g, i} R T_{g, i}, \quad(i=1, \ldots, N) .
\end{gathered}
$$

In this paper, the whole system includes three piston rings and five gas zones that are formed by rings, piston, and liner as sketched in Figure 3. Gas temperatures in the land volumes and groove volumes are assumed to be equal to the instantaneous area-weighted average of the temperature of surfaces surrounding each volume. And those temperatures and volumes would be gotten by the thermomechanical analysis of piston. In this study, an efficient method utilizing the concept of inverse heat conduction based on the FEA is presented for the thermal analysis of piston.

\section{Thermomechanical Analysis of Piston Based on Using the Inverse Heat Conduction Method}

According to the structure of piston head and bore, shown in Figure 3, in order to get the gas temperatures in land volumes and groove volumes, it is important to know the temperature distribution of piston head and bore. In recent years, finite element method has been used to calculate piston temperature [21-29]. It should be noticed that after having identified one correlation for one engine, we acknowledge that those correlation parameters are not valid for another engine with similar characteristics. This is because the convection heat transfer coefficient has many influence factors, and it is hard to give an accurate correlation to describe the distribution of HTC. In this paper, an efficient method utilizing the concept of inverse heat conduction based on the FEA is presented for the thermal analysis of pistons [27]. And using the inverse heat conduction method, the HTC can be effectively determined without giving the correlation.

4.1. Inverse Heat Conduction Method. The relationship between temperature and HTC $\left(h_{c}\right)$ can be given by

$$
T=T\left(h_{c}\right) \text {. }
$$

Thus, the inverse heat conduction problem can be described to find

$$
\sum_{i=1}^{n}\left|\left[T^{\prime}-T\left(h_{c}\right)\right]\right| \longrightarrow \min ,
$$

where $T^{\prime}$ is the real temperature (testing temperature), related to $T\left(h_{c}\right)$ (predicted temperature) and $n$ is the number of conduction segments. Due to the specific piston, the structure of this piston is known, and the HTC is the only unknown parameter. According to (11), if the error between calculated temperature and test temperature can be satisfied, the calculation requirement, the HTC $h_{c}$ can be tried as the real HTC during conduction in real situation. The governing equation of the steady state thermal conduction in the piston can be expressed as [27]

$$
\left.k \frac{\partial T}{\partial n}\right|_{\Gamma}=\left.h_{c}\left(t-T_{f}\right)\right|_{\Gamma}
$$

where $T$ and $k$ represent the temperature and thermal conductivity, respectively. Similar to earlier studies on the thermal analysis of the piston [30], the convection boundary condition can be applied to the piston surface according to the equation as follows:

$$
q=h\left(T-T_{\infty}\right)
$$

where $q, h$, and $T_{\infty}$ represent the outward normal heat flux, the HTC, and the surrounding temperature at the surface, respectively. The surrounding temperature $T_{\infty}$ can be defined as the combustion gas temperature $T_{\text {gas }}$ at the combustion-side top surface of the piston head, the cooling 


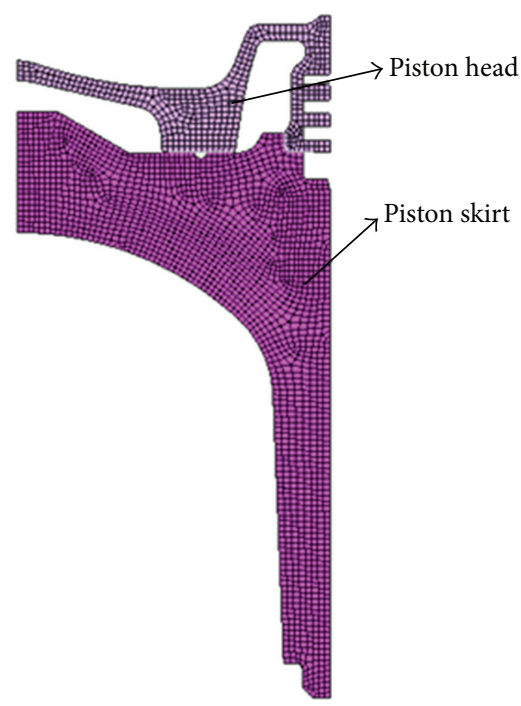

(a) 2D finite element of the piston

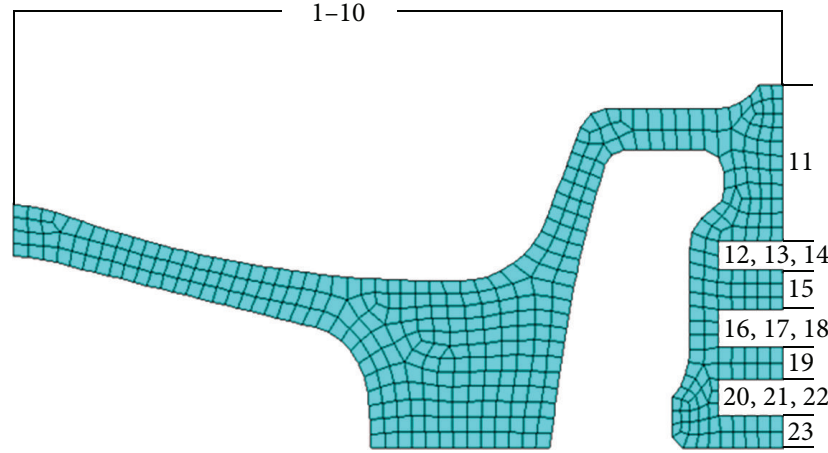

(b) Convection subregion of head

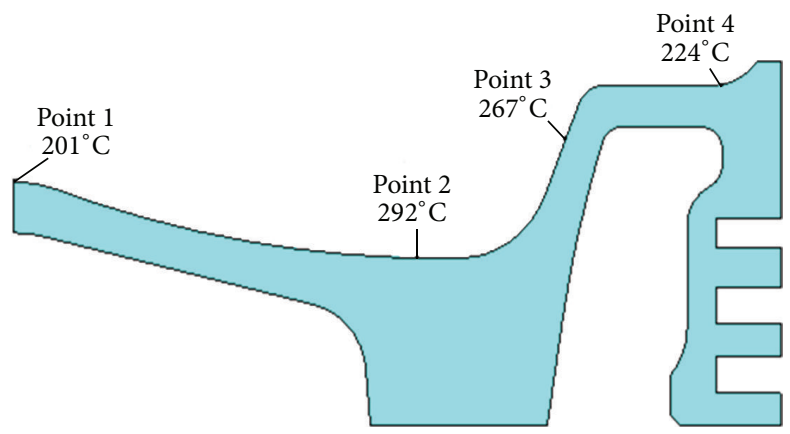

(c) Temperature testing point distribution on the head

FIgURE 4: 2D model of piston.

water temperature $T_{c}$ at the side, and the oil temperature $T_{\text {oil }}$ at the underside and cooling gallery [31].

In order to find an accurate solution to the inverse heat conduction problem, the finite element (FE) method is employed in this study. The 2D FE model of piston is built by quadratic solid 55 elements in order to analyze the axisymmetric problem (as shown in Figure 4(a)). And the head of piston is divided into numerous boundary segments $(n=23)$ of which HTCs are a piecewise constant (as shown in Figure 4(b)). The distribution of testing point is shown in Figure 4(c). Assume the temperature of node $i$ is $T_{i}\left(h_{c}\right)$, and the initial magnitude is $h_{c 0}=\left(h_{c 10}, h_{c 20}, \ldots, h_{c n 0}\right)$. Thus using Taylor's formula, $T_{i}\left(h_{c}\right)$ can be expressed as

$$
\begin{array}{r}
T_{i}\left(h_{c}\right)=T_{i}\left(h_{c 0}\right)+\sum_{j=1}^{n} \frac{\partial T_{i}}{\partial h_{c j}} h_{c j}\left(h_{c j}-h_{c j 0}\right), \\
(i=1,2, \ldots, n) .
\end{array}
$$

If $T_{i}\left(h_{c}\right)=T_{i}$, (14) can be written as

$$
\sum_{j=1}^{n} \frac{\partial T_{i}}{\partial h_{c j}} h_{c j}=T_{i}^{\prime}-T_{i}\left(h_{c 0}\right)+\sum \frac{\partial T_{i}}{\partial h_{c j}} h_{c j 0} .
$$

Thus, those equations can compose a linear equation system relating to $\left(h_{c 1}, h_{c 2}, \ldots, h_{c n}\right)$, and it can be written as

$$
\mathbf{W h}_{\mathbf{c}}=\mathbf{P},
$$

where the HTC matrix $\mathbf{h}_{\mathbf{c}}=\left(h_{c 1}, h_{c 2}, \ldots, h_{c n}\right)^{T}$, the equation coefficient matrix $\mathbf{W}=\left[\begin{array}{ccc}w_{11} & \cdots & w_{1 n} \\ & \cdots & \\ & \cdots & w_{n n}\end{array}\right]$, and each element can be calculated by

$$
w_{j k}=\left.\frac{\partial T_{i}}{\partial h_{c k}}\right|_{h_{c k}=h_{c k 0}} .
$$

And $P=\left\{P_{1}, P_{2}, \ldots, P_{n}\right\}$; vector element in this matrix can be given by

$$
P_{k}=T_{i}^{\prime}-T_{i}+W h_{c 0} .
$$

If the partial derivative of each HTC is known, the solution is the optimum solution. However, it is hard to know the linear correlation between HTC and temperature and the following equation can be used to get the better approximate solution:

$$
[K]\{T\}=\{P\},
$$




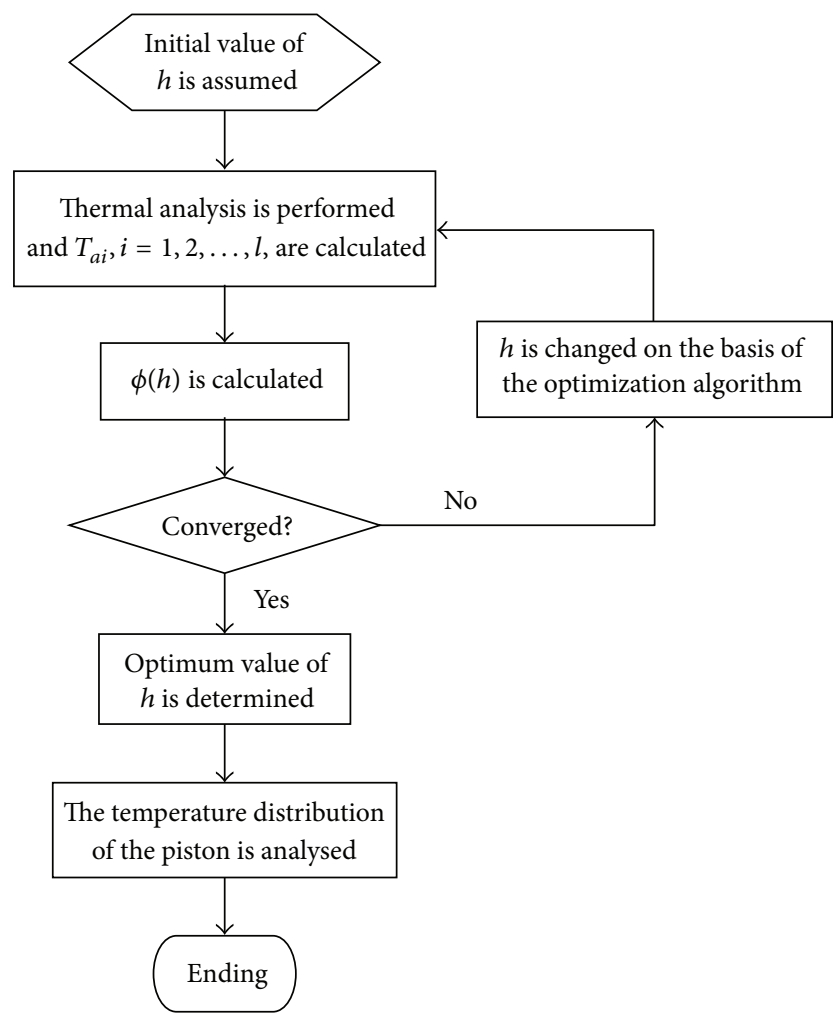

FIgURE 5: Procedure to solve the inverse heat conduction problem.

where $\{T\}$ is the predicted temperature which is unknown and $[K]$ is the function of HTC and heat conductivity coefficient (HCC); it can be given as $K=f\left(k, h_{c}\right)$. There are a number of partial derivatives in (19). In order to improve the solving accuracy, the first-order method of the ANSYS design optimization module is used in this study.

4.2. Numerical Simulation Procedure. The inverse heat conduction problem of the equation above can be solved using the optimization technique; the procedure to solve the problem is described in Figure 5. The HTC varies depending on the location of the piston surface. The HTC at the surface of head, excluding the piston head, is determined by $\mathrm{Lu}$ et al. [31], and the initial value of all design variables, that is, the HTC, is set uniformly as $100 \mathrm{~W} / \mathrm{m}^{2} \mathrm{~K}$. An inverse heat conduction problem to determine $h_{i}$ can be formulated as an optimization problem as finding [32]

$$
h \equiv\left\{h_{1}, \ldots, h_{n}\right\}
$$

to minimize

$$
\phi(h) \equiv \sum_{i=1}^{l}\left(T_{a i}-T_{m i}\right)^{2} .
$$

The numerical implementation to solve the optimization problem is performed by ANSYS. The first-order method of the ANSYS design optimization module is used, the gradients being calculated with a design variable increment of 0.05 percent of the difference between the upper and lower

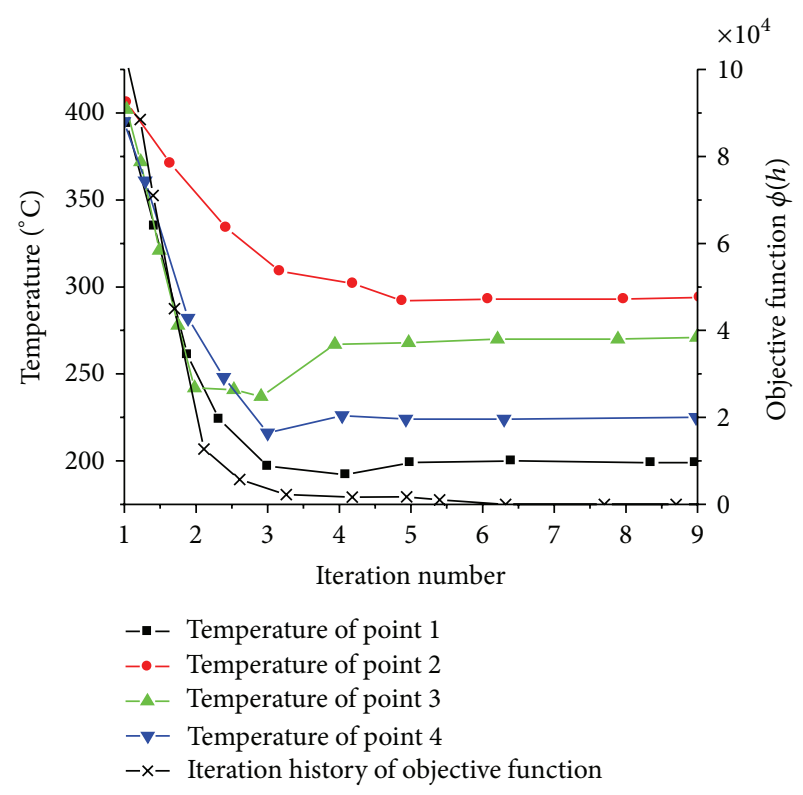

FIGURE 6: Iteration history of the objective function and temperatures of testing point.

TABLE 1: Comparison of the measured temperatures and the predicted temperatures with the optimum HTC.

\begin{tabular}{lccc}
\hline $\begin{array}{l}\text { Measurement } \\
\text { points }\end{array}$ & $\begin{array}{c}\text { Predicted } \\
\text { temperature } \\
T_{m i}{ }^{\circ} \mathrm{C}\end{array}$ & $\begin{array}{c}\text { Measured } \\
\text { temperature } \\
T_{a i}{ }^{\circ} \mathrm{C}\end{array}$ & $\begin{array}{c}\left|\left(T_{m i}-T_{a i}\right) / T_{a i}\right| \\
(\%)\end{array}$ \\
\hline Point 1 & 197.25 & 201 & 1.9 \\
Point 2 & 291.31 & 292 & 0.23 \\
Point 3 & 268.15 & 267 & 0.43 \\
Point 4 & 222.68 & 224 & 0.59 \\
\hline
\end{tabular}

bounds. The acceptable change in the design variables between iterations for convergence is set as $0.01 *$ current value.

\section{Results and Discussion}

5.1. Temperature Distribution and Thermal Deformation of Piston Lands and Grooves. The optimization problem for the piston is analyzed. Less than 9 iterations are taken to obtain the optimum solutions; the history of the objective function and testing points' temperature during iterations is shown in Figure 6. The initial optimum value of the objective function is very large and the optimum value of objective function is very close to zero. As an inverse problem, the temperatures of testing points become close to the test value (shown in Figure 6) very fast. And the temperature distributions calculated by initial and optimum value of the HTC are shown in Figure 7. The analyzed temperature using the optimum HTC is compared with the measured temperature in Table 1. Note that the maximum error is less than $1.9 \%$. 


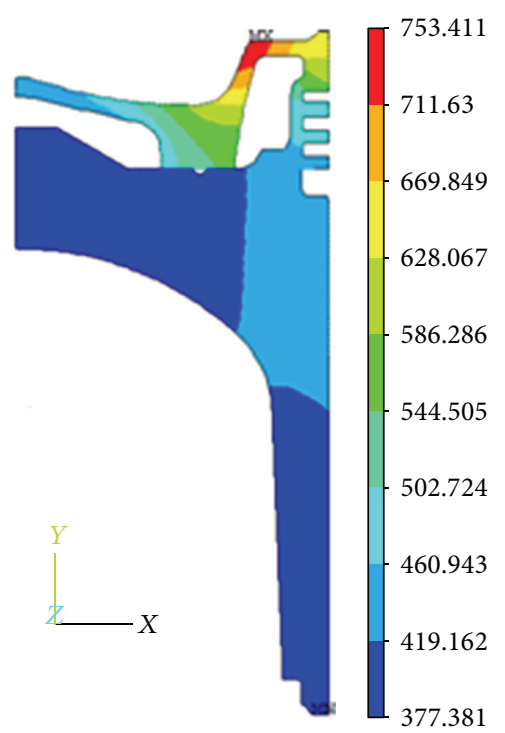

(a) Initial HTC

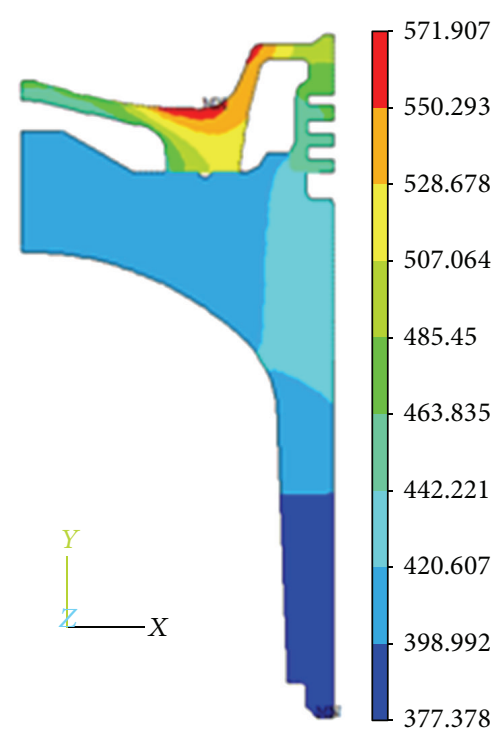

(b) Optimum HTC

FIGURE 7: Temperature distribution of the piston head.
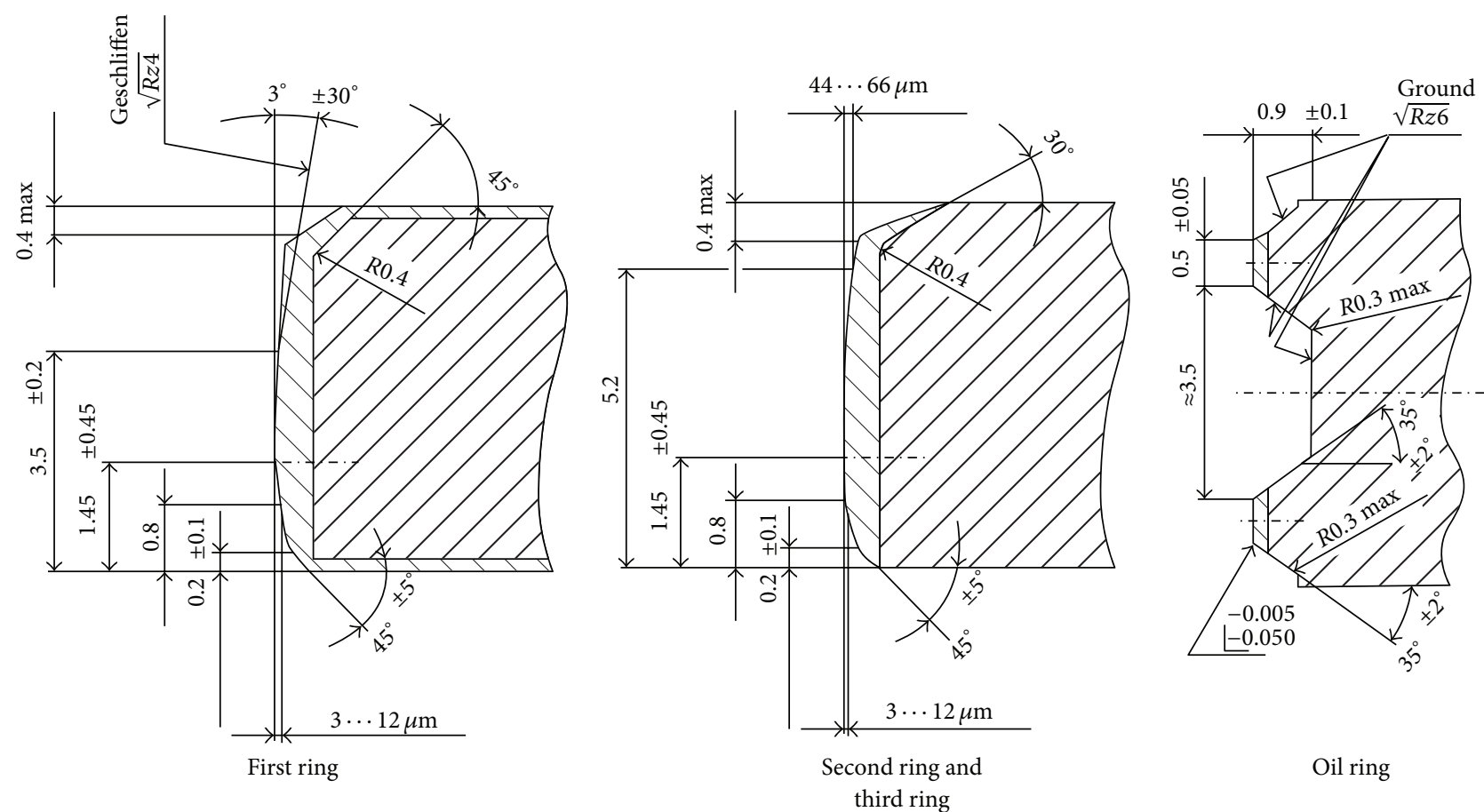

FIGURE 8: The geometry of the piston rings.

5.2. Performance of Ring Pack. The geometry of the piston rings and structure of piston head used in this study are shown in Figures 8 and 9. Each ring is modeled as a single mass; twisting (including pretwist angles) is considered. The equations of motion, which consider equilibrium condition of moments and forces for each ring, are solved. The dynamic components of the ring motion are calculated by means of time integration methods of explicit type. The mechanism of piston ring sealing is equivalent to a labyrinth seal, where the gap clearances are determined by the actual position of the rings in the groove in consideration of the global movement and tilting of the piston [33]. The law for isotropic flow of ideal gas is used for the calculation of the gas flows, as (9) showed. The calculation of the updated gas pressures due 


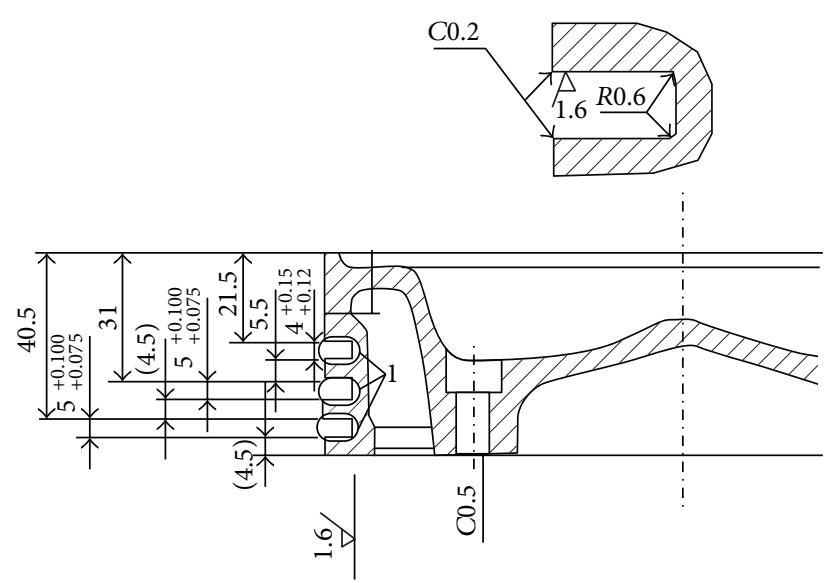

FIGURE 9: The structure of piston head.

TABLE 2: The temperature distribution of piston grooves and lands.

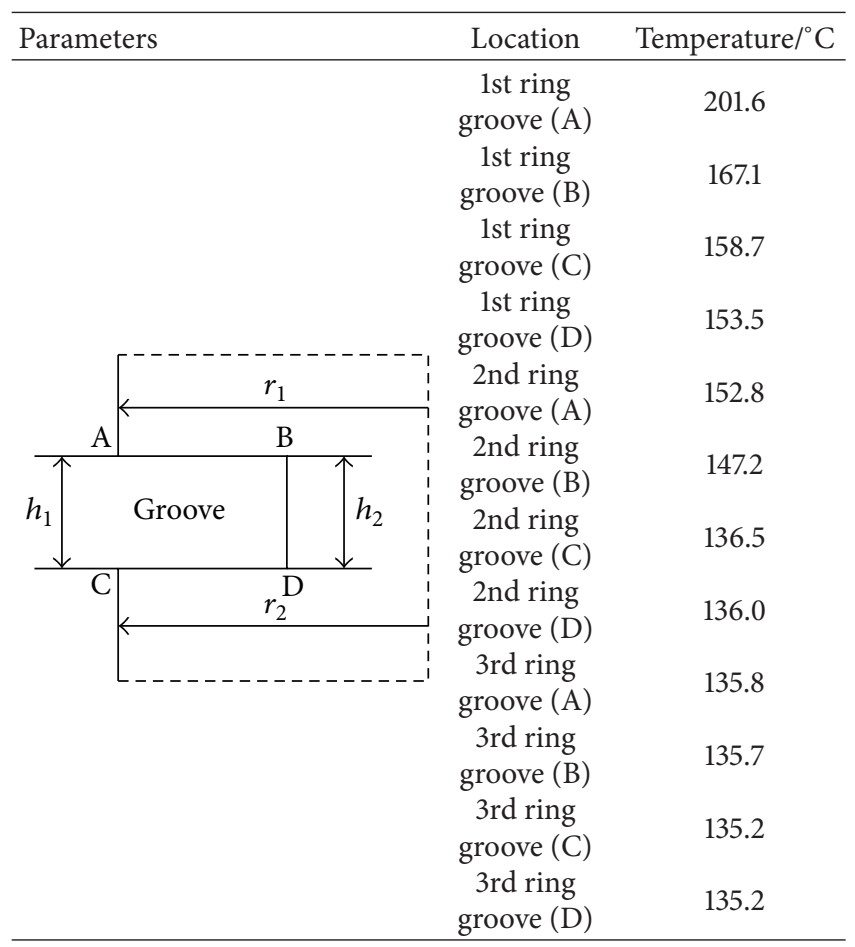

to changes in mass and vessel volume is described by the isotherm equation of state. The particular piston temperature and thermal deformation are given by FEA, listed in Tables 2 and 3. The Reynolds equations are solved iteratively in each time step to determine the hydrodynamic pressure distribution between ring running surface and liner. The last part of the simulation procedure deals with the evaluation of oil consumption to the combustion gas [34] and the friction loss $[35,36]$. All relevant mechanisms are considered; the calculation is done quasistatically per time step, and the program code is designed by Fortran.

5.2.1. The Pressure Distribution in Ring Grooves and Piston Lands. The calculated axial position of rings in grooves is
TABLE 3: Deformation of grooves and lands.

\begin{tabular}{lc}
\hline Parameters & Value $(\mu \mathrm{m})$ \\
\hline 1st ring groove & \\
$\Delta h 1$ & -35 \\
$\Delta h 2$ & -2 \\
$\Delta r 1$ & 267 \\
$\Delta r 2$ & 255 \\
2nd ring groove & \\
$\Delta h 1$ & -19 \\
$\Delta h 2$ & 1 \\
$\Delta r 1$ & 247 \\
$\Delta r 2$ & 240 \\
$3 r d$ ring groove & \\
$\Delta h 1$ & 4 \\
$\Delta h 2$ & 7 \\
$\Delta r 1$ & 243 \\
$\Delta r 2$ & 259 \\
\hline
\end{tabular}

Positive $=$ increase; negative $=$ decrease .

TABLE 4: The friction loss, blowby, and oil consumption considering thermal effect.

\begin{tabular}{|c|c|c|c|}
\hline \multicolumn{3}{|c|}{ Friction loss (kW) } & \\
\hline First ring & $\begin{array}{l}\text { Second } \\
\text { ring }\end{array}$ & Third ring & $\begin{array}{c}\text { Total loss }(\mathrm{kW}) \text { consumption } \\
(\mathrm{g} / \mathrm{h})\end{array}$ \\
\hline 3.4191 & 1.3196 & 1.2451 & 5.9837 \\
\hline \multicolumn{3}{|c|}{ Inverse blowby* $(\mathrm{g} / \mathrm{s})$} & \multirow[t]{2}{*}{ Average blowby (g/s) } \\
\hline First ring & $\begin{array}{l}\text { Second } \\
\text { ring }\end{array}$ & Third ring & \\
\hline-7.6367 & -0.2203 & 0.00000 & 0.9675 \\
\hline
\end{tabular}

shown in Figure 10. Wear of the parallel surfaces in piston ring grooves, commonly called ring groove wear, occurs mainly in the top groove. The main reason for the wear is the combined effect of gas forces and radial motion of the ring, and the wear process is accelerated by poor lubrication and a high temperature. The reasons for the radial motion of the ring are the cylinder distortion, the secondary movement of the piston, and piston tilt allowed by the piston/cylinder clearance. Mass forces, friction forces, axial ring movement, and ring rotation increase the ring groove wear. Instationary gas pressure and gas blowby may cause radial vibrations in the ring, which accelerates the ring groove wear at the ring groove contact areas [37]. And the friction loss and gas blowby at the piston rings are summarized in Table 4 . It is clear that the ratios of the first ring in friction loss and inverse blowby are majority ( $57.14 \%$ and $97.44 \%$, resp.), and this means the design of the first ring groove is significant for the piston design.

5.2.2. Piston Groove Parameters Sensitive Analysis. Blow-by gas flow refers to the undesired gas flow from the combustion chamber to the crankcase. It reduces the efficiency of engine and contaminates oil with the combustion products present 
TABLE 5: An analysis of variance table for the simple linear regression model.

\begin{tabular}{|c|c|c|c|c|c|}
\hline Source & SS (sums of squares) & df (degrees of freedom) & MS (mean squares) & $F$-statistic & Significance $F$ \\
\hline Regression & $\mathrm{SS}_{R}$ & $\mathrm{df}_{R}=m$ & $\mathrm{MS}_{R}$ & \multirow{2}{*}{$F=\mathrm{MS}_{R} / \mathrm{MS}_{r}$} & \multirow{2}{*}{$F_{\alpha}(m, n-m-1)$} \\
\hline Residual & $\mathrm{SS}_{r}$ & $\mathrm{df}_{r}=n-m-1$ & $\mathrm{MS}_{r}$ & & \\
\hline Total & $\mathrm{SS}_{T}$ & $\mathrm{df}_{T}=n-1$ & & & \\
\hline
\end{tabular}

TABLE 6: Analysis of variance table for the multiple linear regression $(\Delta h 1)$.

\begin{tabular}{lccccc}
\hline Source & SS & df & MS & $F$ & Significance $F$ \\
\hline Regression & $2.75 E-03$ & 3 & $9.18 E-04$ & $3.00 E+07$ & $F_{0.05}(3,1)=216$ \\
$\Delta h 1(1)$ & $4.00 E-08$ & 1 & $4.00 E-08$ & $\sim 21 E+03$ & $F_{0.01}(3,1)=540$ \\
$\Delta h 1(2)$ & 0 & 1 & 0 & $\sim 0$ & $F_{0.05}(1,1)=161$ \\
$\Delta h 1(3)$ & 0 & 1 & 0 & $F_{0.01}(1,1)=405$ \\
Residual & $3.06 E-11$ & 1 & 1.1867 & \\
\hline Total & $2.75 E-03$ & 2 & & \\
\hline
\end{tabular}

TABLE 7: Analysis of variance table for the multiple linear regression $(\Delta h 2)$.

\begin{tabular}{lccccc}
\hline Source & SS & df & MS & $F$ & Significance $F$ \\
\hline Regression & $2.65 E-03$ & 3 & $9.12 E-04$ & $2.92 E+07$ & $F_{0.05}(3,1)=216$ \\
$\Delta h 2(1)$ & $3.82 E-08$ & 1 & $3.82 E-08$ & $1.21 E+03$ & $F_{0.01}(3,1)=540$ \\
$\Delta h 2(2)$ & 0 & 1 & 0 & $\sim 0$ & $F_{0.05}(1,1)=161$ \\
$\Delta h 2(3)$ & 0 & 1 & 0 & $F_{0.01}(1,1)=405$ \\
Residual & $3.00 E-11$ & 1 & 1.1277 & \\
\hline Total & $2.75 E-03$ & 2 & & \\
\hline
\end{tabular}

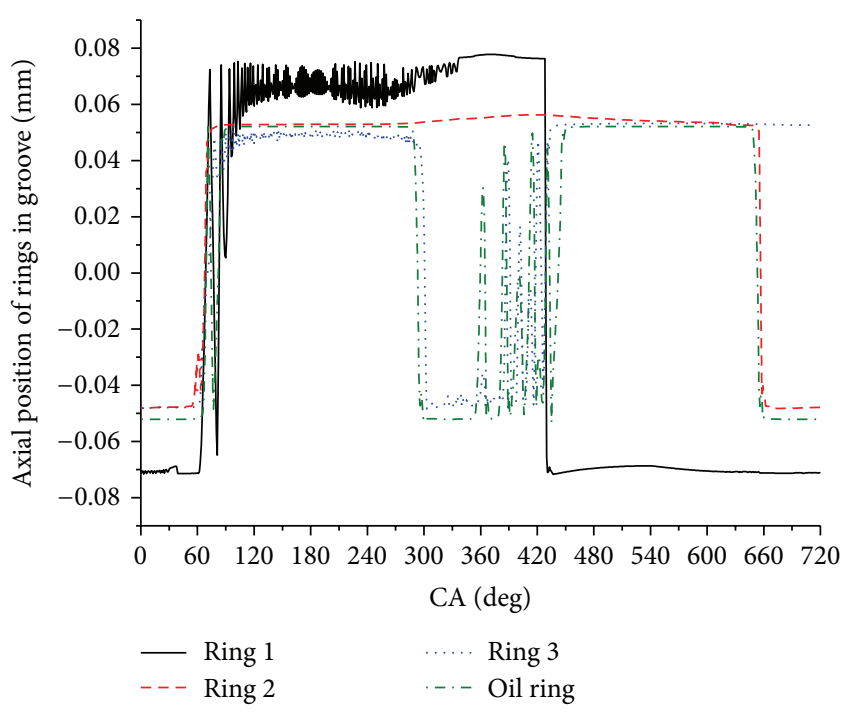

FIGURE 10: The axial position of rings in grooves.

in the gases. The ring pack system serves as a channel for blow-by gases. As a result, it is important for engine manufacturers and lubricant suppliers to optimize ring pack system to take it into account in controlling oil consumption resulting from blow-by gases. In order to investigate the effect of groove parameters on blowby, a sensitive analysis based on the analysis of partial regression coefficients and an analysis of variance (ANOVA) table for the simple linear regression model can be given in Table 5 [38]. During the multiple linear regression (MLR) analysis, the blowby of first ring is the dependent variable (DV), and the parameters of groove, such as $\Delta h 1(i), \Delta h 2(i), \Delta r 1(i)$, and $\Delta r 2(i)(i$ is the number of grooves) shown in Table 2 , are the independent variables (IVs). In this study, when one IV increased by one unit $(1 \mathrm{~mm}$ ), all the other IVs are held constant (as shown in Table 3). The analysis results of multiple linear regression related to the groove parameters are listed in Tables $6-9$, respectively. Based on those tables, it is obvious that $\Delta h 1(1)$ and $\Delta h 2(1)$ have significant influence on blow-by gas flow and other parameters without any obvious impact on it. Due to the thermal effect on $\Delta h 1(1)$ and $\Delta h 2(1)$, the interring gas dynamic analysis should consider the thermal effect.

\section{Conclusions}

The present work features detailed interring gas dynamics of piston ring pack behavior in internal combustion engines. The model is developed for a ring pack with four rings. The dynamics of ring pack are simulated. Due to the fact that small changes in geometry of the grooves and lands would have a significant impact on the interring gas dynamics, the thermal deformation of piston and bore has been considered during the ring pack motion analysis in this study. In order to get the temperature distribution of piston head more quickly and accurately, an efficient method utilizing the concept of inverse heat conduction is presented. The result of the temperature analyzed using the optimum HTC is compared 
TABLE 8: Analysis of variance table for the multiple linear regression $(r 1)$.

\begin{tabular}{lccccc}
\hline Source & SS & df & MS & $F$ & Significance $F$ \\
\hline Regression & $2.75 E-03$ & 3 & $9.17 E-04$ & $3.06 E+02$ & $\sim 0$ \\
$r 1(1)$ & $-2.21 E-12$ & 1 & $-2.21 E-12$ & $\sim 0$ & $F_{0.05}(3,1)=216$ \\
$r 1(2)$ & 0 & 1 & 0 & $\sim 0$ & $F_{0.01}(3,1)=540$ \\
$r 1(3)$ & 0 & 1 & 0 & $F_{0.05}(1,1)=161$ \\
Residual & $2.99 E-06$ & 1 & $2.99 E-06$ & $F_{0.01}(1,1)=405$ \\
\hline Total & $2.75 E-03$ & 2 & & \\
\hline
\end{tabular}

TABLE 9: Analysis of variance table for the multiple linear regression $(r 2)$.

\begin{tabular}{lccccc}
\hline Source & SS & df & MS & $F$ & Significance $F$ \\
\hline Regression & $2.66 E-03$ & 3 & $8.86 E-04$ & $9.30 E+00$ & $\sim 0$ \\
$r 2(1)$ & $-5.50 E-18$ & 1 & $-5.50 E-18$ & $\sim 0$ & $F_{0.05}(3,1)=216$ \\
$r 2(2)$ & $1.44 E-18$ & 1 & $1.44 E-18$ & $F_{0.01}(3,1)=540$ \\
$r 2(3)$ & $3.77 E-18$ & 1 & $3.77 E-18$ & $F_{0.05}(1,1)=161$ \\
Residual & $9.53 E-05$ & 1 & $9.53 E-05$ & $F_{0.01}(1,1)=405$ \\
\hline Total & $2.75 E-03$ & 2 & & \\
\hline
\end{tabular}

with the measured temperature, and reasonable agreement is obtained. Moreover, a sensitive analysis based on the analysis of partial regression coefficients is presented to investigate the effect of groove parameters on blowby. And the result shows that $\Delta h 1(1)$ and $\Delta h 2(1)$ (shown in Table 2) have significant influence on blow-by gas flow, while other parameters have no obvious impact on it. As the thermal effect on $\Delta h 1(1)$ and $\Delta h 2(1)$, the interring gas dynamic analysis should consider the thermal effect.

\section{Conflict of Interests}

The authors declare that they have no conflict of interests regarding this work.

\section{Acknowledgments}

The present research has been funded by National Natural Science Foundation of China (Grant no. 51375104) and Fundamental Research Funds for the Central Universities (Code HEUCFZ1117). The authors would like to sincerely express their appreciation.

\section{References}

[1] L. L. Ting and J. E. Mayer, "Piston ring lubrication and cylinder bore wear analysis, part I-theory," Journal of Lubrication Technology, vol. 96, pp. 305-314, 1974.

[2] L. L. Ting and J. E. Mayer, "Piston ring lubrication and cylinder bore wear analysis, part II-theory verification," Journal of Tribology, vol. 96, no. 2, pp. 258-266, 1974.

[3] D. Dowson, P. N. Economou, and B. L. Ruddy, "Piston ring lubrication-part II: theoretical analysis of a single ring and complete ring pack," in Energy Conservation Through Fluid Film Lubrication Technology: Frontiers in Research and DesignWinter Annual Meeting of the ASME, pp. 23-52, 1979.
[4] B. L. Ruddy, D. Dowson, and P. N. Economou, "Piston ring lubrication, Part III: the influence of ring dynamics and ring twist," in Proceedings of the Winter Annual Meeting of ASME: Energy Conservation Through Fluid Film Lubrication Technology: Frontiers in Research and Design, pp. 191-215, 1979.

[5] B. L. Ruddy, D. Dowson, and P. N. Economou, "A theoretical analysis of the twin-land type of oil-control piston ring," Journal of Mechanical Engineering Science, vol. 23, no. 2, pp. 51-62, 1981.

[6] S. M. Rhode, "A mixed friction model for dynamically loaded contacts with application to piston ring lubrication," in Proceedings of the 7th Leeds-Lyon Symposium on Tribology, p. 262, Westbury House, September 1980.

[7] R. Truscott, T. J. Reid, and B. L. Ruddy, "Ring dynamics in a diesel engine and its effects on oil consumption and blowby," SAE Paper 831282, SAE, 1983.

[8] B. L. Ruddy, T. J. Reid, and A. Veshagh, "Ring pack performance predictions," in Proceedings of the AE Symposium, Paper No. 30, 1986.

[9] T. J. Banks and D. J. Lacy, “The application of analysis to piston ring performance," IMechE paper No. C375/003, 1989.

[10] K. Maekawa, S. Mitsutake, and S. Morohoshi, "A study of engine lubricating oil consumption by computer simulation," SAE Paper 860546, 1986.

[11] R. Munro, "Emissions impossible-the piston and ring support system," SAE Paper 900590, 1990.

[12] R. Keribar, Z. Dursunkaya, and M. F. Flemming, "Integrated model of ring pack performance," Journal of Engineering for Gas Turbines and Power, vol. 113, no. 3, pp. 382-389, 1991.

[13] R. Rabuté and T. Tian, "Challenges involved in piston top ring designs for modern SI engines," Journal of Engineering for Gas Turbines and Power, vol. 123, no. 2, pp. 448-459, 2001.

[14] T. Tian, L. B. Noordzij, V. W. Wong, and J. B. Heywood, "Modeling piston-ring dynamics, blowby, and ring-twist effects," Journal of Engineering for Gas Turbines and Power, vol. 120, no. 4, pp. 843-854, 1998.

[15] M. A. Ejakov, H. J. Shock, and L. J. Brombolich, "Modeling of ring twist for an IC engine," SAE Paper 982693, SAE, 1998.

[16] Y. Hu, H. S. Cheng, T. Arai, Y. Kobayashi, and S. Aoyama, "Numeric simulation of piston ring in mixed lubrication-a 
nonaxisymmetrical analysis," Journal of Tribology, vol. 116, no. 3, pp. 470-478, 1994.

[17] M.-T. Ma, I. Sherrington, and E. H. Smith, "Analysis of lubrication and friction for a complete piston-ring pack with an improved oil availability model part 1: circumferentially uniform film," Proceedings of the Institution of Mechanical Engineers Part J: Journal of Engineering Tribology, vol. 211, no. 1, pp. 1-15, 1997.

[18] M.-T. Ma, I. Shcrrington, and E. H. Smith, "Analysis of lubrication and friction for a complete piston-ring pack with an improved oil availability model. Part II: circumferentially variable film," Proceedings of the Institution of Mechanical Engineers Part J: Journal of Engineering Tribology, vol. 211, no. 1, pp. 17-27, 1997.

[19] L. Liu, Modeling the performance of the piston ring-pack with consideration of non-axisymmetric characteristics of the power cylinder system in internal combustion engines [Ph.D. thesis], Massachusetts Institute of Technology, 2005.

[20] B. Thirouard, Characterization and modeling of the fundamental aspects of oil transport in the piston ring pack of internal combustion engines [Ph.D. thesis], MIT, 2001.

[21] C. H. Li, "Piston thermal deformation and friction considerations," SAE paper 820086, 1982.

[22] M. T. Abbes, P. Maspeyrot, A. Bounif, and J. Frene, "A thermomechanical model of a direct injection diesel engine piston," Proceedings of the Institution of Mechanical Engineers Part D: Journal of Automobile Engineering, vol. 218, no. 4, pp. 395-409, 2004.

[23] Y. Liu and R. D. Reitz, "Multidimensional modeling of combustion chamber surface temperatures," SAE Paper 971539, 1997.

[24] R. J. Jcnkin, E. H. James, and W. Malalasckcra, "Modelling the effects of combustion and turbulence on near-wall temperature gradients in the cylinders of spark ignition engines," Proceedings of the Institution of Mechanical Engineers, Part D: Journal of Automobile Engineering, vol. 212, no. 6, pp. 533-546, 1998.

[25] S. V. Bohac, D. M. Baker, and D. N. Assanis, "A global model for steady state and transient SI engine heat transfer studies," SAE Paper 960073, SAE, 1996.

[26] V. Esfahanian, A. Javaheri, and M. Ghaffarpour, "Thermal analysis of an SI engine piston using different combustion boundary condition treatments," Applied Thermal Engineering, vol. 26, no. 2-3, pp. 277-287, 2006.

[27] B. Y. Lee and W. J. Kim, "Thermal analysis of a liquidpetroleum-liquid injection engine piston using the inverse heat conduction method," Proceedings of the Institution of Mechanical Engineers Part D: Journal of Automobile Engineering, vol. 222, no. 6, pp. 1033-1045, 2008.

[28] G. Li, 3D steady thermal analysis and intensity calculation for piston [M.S. thesis], Harbin Engineering University, Harbin, China, 2006.

[29] D.-M. Lou, Z.-Y. Zhang, and L.-L. Wang, "Heat transfer boundary condition and thermal load of combined-piston for locomotive diesel engines," Journal of Tongji University, vol. 33, no. 5, pp. 664-667, 2005 (Chinese).

[30] X.-Q. Lu, T. He, D.-Q. Zou, Y.-B. Guo, and W.-Y. Li, “Thermal analysis of composite piston in marine diesel engine based on inverse evaluation method of heat transfer coefficient," Chinese Internal Combustion Engine Engineering, vol. 33, no. 4, pp. 7176, 2012.

[31] X. Lu, Q. Li, W. Zhang, Y. Guo, T. He, and D. Zou, "Thermal analysis on piston of marine diesel engine," Applied Thermal Engineering, vol. 50, no. 1, pp. 168-176, 2013.
[32] T. He, X. Q. Lu, and Y. B. Guo, "Analysis of the heat transfer coefficients on the top of a marine diesel piston using the inverse heat conduction method," Advanced Materials Research, vol. 291-294, pp. 1657-1661, 2011.

[33] R. J. Gamble, M. Priest, R. J. Chittenden, and C. M. Taylor, "Preliminary study of the influence of piston secondary motion on piston ring tribology," Tribology Series, vol. 38, pp. 679-691, 2000.

[34] S. M. Chun, "Simulation of engine life time related with abnormal oil consumption," Tribology International, vol. 44, no. 4, pp. 426-436, 2011.

[35] S.-W. Cho, S.-M. Choi, and C.-S. Bae, "Frictional modes of barrel shaped piston rings under flooded lubrication," Tribology International, vol. 33, no. 8, pp. 545-551, 2000.

[36] G. A. Livanos and N. P. Kyrtatos, "Friction model of a marine diesel engine piston assembly," Tribology International, vol. 40, no. 10-12, pp. 1441-1453, 2007.

[37] K. Mollenhauer, Diesel Engine, Springer, Berlin, Germany, 1997, (German).

[38] http://wenku.baidu.com/view/857487d5360cbalaa811da03.html. 


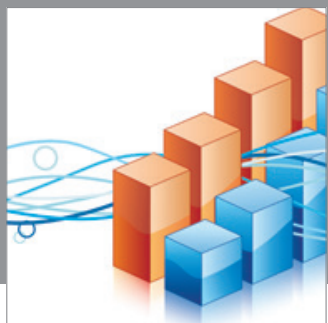

Advances in

Operations Research

mansans

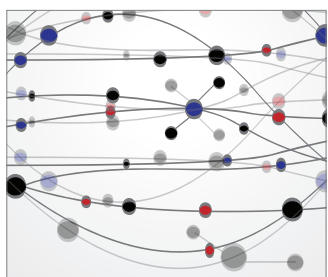

The Scientific World Journal
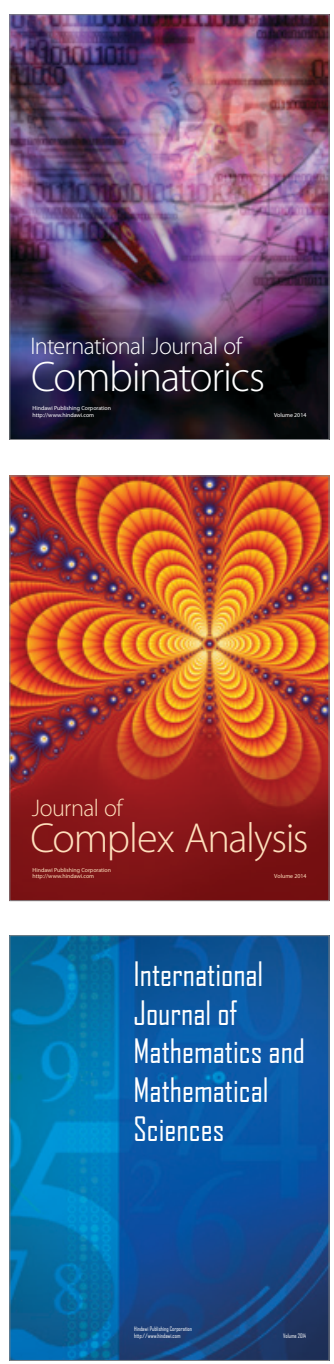
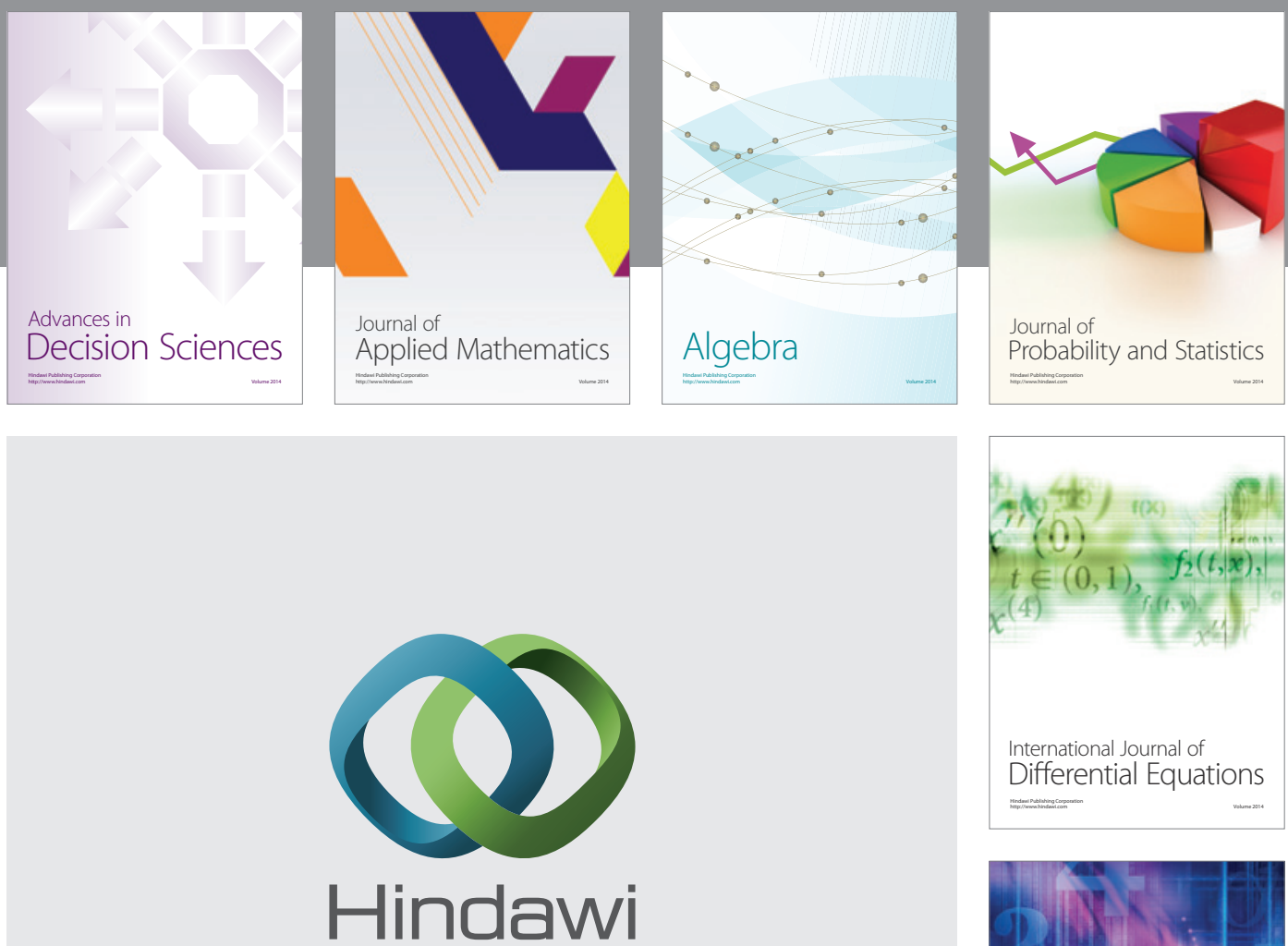

Submit your manuscripts at http://www.hindawi.com
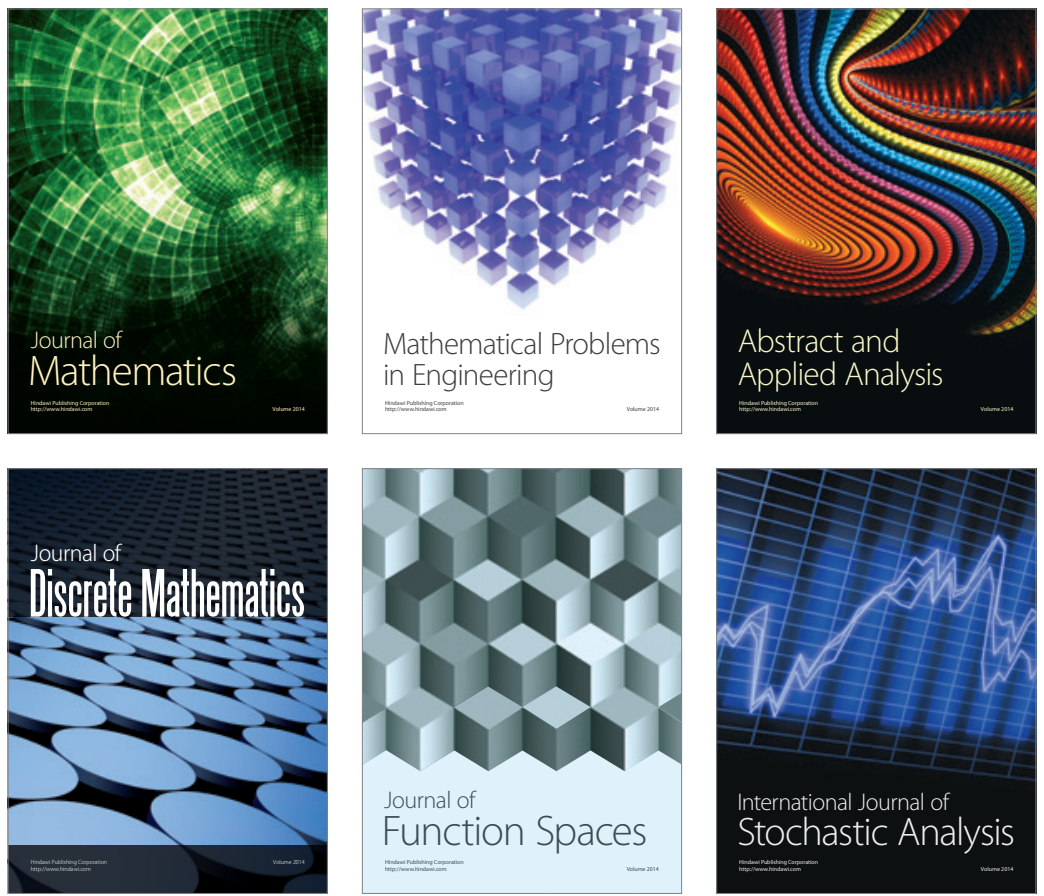

Journal of

Function Spaces

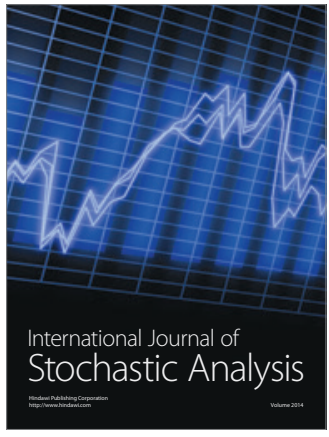

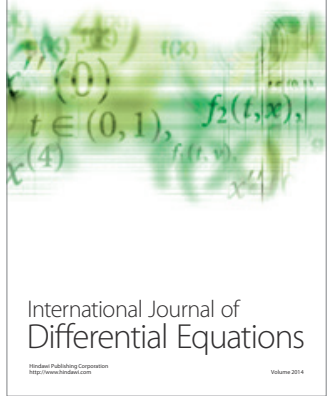
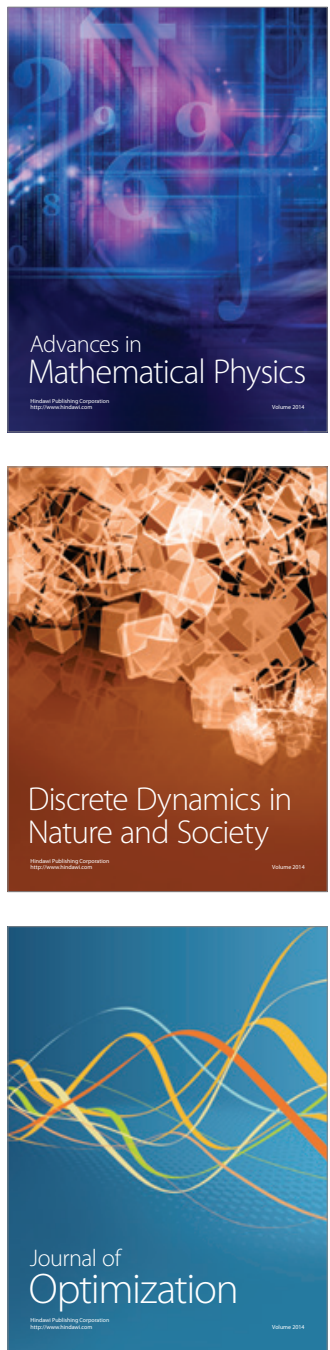